\title{
INAUGURAL ADDRESS.
}

React before the Institution at Leeds, by Mr. H. N. GRESLEY, Doncaster, Chairman of Committee (Ledds Centre), on Saturiay, May IIth, $19 I 8$.

The Chairman: Gentlemen, I think that the best way of starting our proceedings this afternoon will be for me to call upon Colonel Kitson Clark to explain to you the inception of this Local Centre of the Institution of Locomotive Engineers. On the ccasion when the scheme was brought before a number of engineers in this district I was unfortunately unable to be present, and as Colonel Kitson Clark was. Chairman at that meeting I think I cannot do better than ask hin to open the proceedings.

Colonel Kitson Clark (Vice-Chairman): Mr. Chairman and Gentlemen, I thank you for the task which you put into my hands, more particularly in view of the excellent prospects of the Institution in Leeds. Certain members of the Council of the Institution in London communicated with gentlemen who were interested in locomotive work in this district. They did me the honour to invite me to become Chairman at the first meeting, which was held on March 2nd. The general rules were recited and explained by Mr. Lelean, a member of the Council. They enacted that there should be a local Centre controlled by a Committee, with a Chairman. The duties of the Committee should be to arrange for papers to be read, works to be visited, and membership applied for, according to the Articles of Association. And I had the pleasure of proposing that Mr. Gresley should act as Chairman. That naturally was received with acclamation, and, some days later, after persuasion, Mr. Gresley accepted the situation. There was a good general discussion on March 2nd, and we had a very pleasant afternoon; I think now you have got as far as I have, so I have great pleasure in calling upon Mr. Gresley as our first Chairman, at our first meeting.

The Chairman : Gentlemen, on an occasion like this, I am told by the Committee of which I am Chairman, that it is customary to give an inaugural address. First of all, I am not the President; I am Chairman of the Leeds Local 
Centre. The President of the Institution of Locomotive Engineers is, of course, the President of the main body which sits in London.

In inviting me to become your first Chairman of the Local Centre which has been formed of the Institution of Locomotive Engineers in Leeds I appreciate the compliment thereby paid to the Locomotive Department of the Great Northern Railway.

The Great Northern Railway has for many years been intimately connected with Leeds, and the patronage it has enjoyed is a sufficient testimony to the excellence of the service which it has rendered.

In the days of strenuous competition with other railways for the Leeds and London traffic, the Great Northern has always more than held its own; this is without doubt largely due to the comfort, speed and punctuality of its service, for which the Locomotive Department has principally been responsible. For these results my predecessors are responsible, and I have only had to carry on their good work.

But I want to say that we have not met here to eulogise the Great Northern, or the work of its locomotives. We are here to inaugurate the Local Centre of the Institution of Locomotive Engineers.

The fact of this Institution having the temerity to start a new Centre during these critical times is not only an indication of the national spirit of the country, notwithstanding the anxious times through which we are passing, but is also a proof of the virility and enterprise of this young and vigorous Institution.

Many would hesitate to embark upon such a project when the energies of its members and prospective members are so fully absorbed in war work. But to those who are really interested in the objects of the Institution, the meetings should afford a deep interest, an opportunity of exchanging experiences, and the advancement of this specialised branch of the mechanical engineering profession.

It will be noticed in the constitution of the Committee that there is a substantial representation of the carriage and wagon interest. Although, from a mechanical engineering point of view, the scope for scientific advancement in the construction of carriages and wagons may not appear to be as great as in the locomotive, yet from what is rather a Civil Engineer's standpoint, in that he is more intimately 
connected with the design of structures, both the carriage and the wagon afford scope for improvement in design.

The reduction in the ratio of tare to carrying capacity appeals strongly to the locomotive engineer, and when he is responsible for the work of both these departments of a Railway Company he is always ready to consider any new design which may tend to reduce the weight of trains, which at the same time does not involve any decrease in the strength and endurance of the carriage or wagon stock.

The Institution is therefore well advised in bringing the carriage and wagon section well to the forefront, and I trust that some instructive papers dealing with this section of the work of the Institution will be forthcoming during my year of Chairmanship.

It is now just 25 years since I started at Crewe Works in an atmosphere of compounds in the locomotive engineering profession. You must pardon me if I go back a little. When the 2-2-2-2 type, "Greater Britain," was built it was thought that the limit in size and power of the locomotive had been almost reached, and when in an excess of loyal zeal she was painted crimson, and another engine of the same class "Queen Empress" was painted white at the time of the Queen's Diamond Jubilee, surely the limits of the artistic resource of the locomotive engineer were attained. How long they ran in their splendour I do not recollect, but I remember that the "Greater Britain " was re-christened by the enginemen the "Scarlet Runner," and the delicate hue of the "Queen Empress" began to darken like a wellbehaved meerschaum pipe.

But there was no lack of enterprise in those days at Crewe; a triple expansion engine was tried, a figure 8 firebox, and several boilers with a water space underneath and at the sides of the ashpan were built. Although it would not appear that the evaporative capacity of the ashpan was likely to lead to much increased efficiency, it at any rate provided a suitable receptacle for the accumulation of sludge and scale.

Then I remember an attempt to do away with coupling rods, by the provision of a friction wheel, held up tightly between the coupled wheels by a steam cylinder, and which was to be released when once the engine got away with its train. But this proved to be a failure, for when the driving wheels began to slip, instead of the trailing wheels revolving at the same speed a shower of sparks indicated the formation of a flat on the friction wheel. 
I could quote many other experiments of great interest, some of which failed, and some succeeded, but all added to our experience.

The locomotive of to-day is a very different machine to those to which I have just referred. The improvement is chiefly due to a kind of continuous evolution.

During the last ten years this evolutior has been greatly accelerated by the introduction of superheating. I am not going to say much about superheating beyond this-that its full advantages have not yet been appreciated. By the successful adoption of superheating, to a degree of superheat beyond anything at present attempted, it will be possible to obtain much greater advantages from its introduction.

It will probably be of interest to the members if I give some of my experiences with reference to certain debatable points in connection with present day locomotive design.

The power of an engine depends upon its capacity for boiling water. The boiler is therefore without question its most important feature, but many engineers still compare the power of engines by their tractive force only and ignore the boiler.

As a measure of the power of an engine, tractive force is useless unless the boiler is able to supply the necessary steam for long and continuous service.

A boiler which will supply steam when an engine is notched up to 20 per cent. cut-off, and which fails to do so when the engine is let out on a long incline and has to work at 50 or 60 per cent. cut-off, is too small for the cylinders on that particular work. although it might be quite large enough if the engine were only on shunting or intermittent work.

One of the great difficulties in the standardisation of engines to which I will refer later is the variation in the ratio of boiler to cylinders on different railway lines.

Tractive effort, per $s e$, is useless as a comparative measure of the power of engines. On the Great Northern Railway there are two very instructive examples of this fallacy.

Mr. Ivatt's first " Atlantic" engines had comparatively small boilers according to present day practice. The heating surface was $1,44^{2}$ square feet and a grate of $\mathbf{2 6 . 7 5}$ square feet. The large boiler "Atlantics" have 2,500 square feet of heating surface and 3 I square feet of grate. 
Except for the boilers, the engines are identical so far as boiler pressures, cylinders and wheel diameters are concerned. Therefore the tractive powers are equal, but the large boilered "Atlantics" have proved to be much more powerful as express engines than the "Atlantics" with small boilers, and are able to haul much heavier trains and keep time; in fact, there is as much, or more, difference between the large "Atlantics" and the small ones as there is between the small "Atlantics" and the old 4-4-o engines.

Then later on when the 2-6-0 type was introduced the first ten had small boilers-4ft. 8in. diameter. The later ones had boilers $5 \mathrm{ft}$. 6in. diameter, but the grate area was the same in each case, and the engines in other ways were identical.

During the last year's work the ten engines with the smaller boilers consumed about 5lbs. more of coal per mile for the whole year than the engines with the larger boilers, although they were otherwise similar in every respect.

Talking about fireboxes, it may be of interest to record that the wide fireboxes of the "Atlantic" engines introduced by my predecessor, Mr. Ivatt, are more economical from the point of view of life, and I think also from the point of efficiency, than the narrow ones. Recently I had to condemn one of these large fireboxes which had run 420,000 miles. Although the first engine of this type was built 16 years ago none of the boilers have been scrappd, and the first boiler is still running. This is a fair proof of the satisfactory design and work done in connection with the wide firebox and large boiler.

The work done by these engines is as heavy as that done by any passenger engines in the country, and the trains hauled by them often exceed 500 tons behind the tender to-day. These engines have the biggest boilers and the smallest tractive power of any working on the principal railways of this country. I only quote this to illustrate my point on the fallacy of the basis of tractive power as a comparative measure of locomotive power.

Then there is the much debated question of Belpaire and round topped boilers. I have tried to find some explanation for the apparent conviction of certain engineers in the superiority of the Belpaire type. There must be some explanation of this. I venture to suggest that this conviction is the result of their experience. In the case of almost every railway which has adopted the Belpaire box, the firebox roofs of their old round topped boilers were 
stayed by roof bars, which are well-known to be objectionable on account of the difficulty in keeping the firebox-top free from dirt. Naturally, when they introduced Belpaire boxes with direct roof stays, many of the troubles which they previously had with the fireboxes disappeared, and the improvement was put down to the adoption of the Belpaire type boiler. On the other hand, the use of direct stays in round topped boilers has been the general practice on other railways, two of which are well represented here to-day. To such the Belpaire boiler offered no advantage; in fact on one line it was tried and abandoned. I have therefore come to the conclusion that, from a maintenance standpoint, the Belpaire boiler offers no advantages over the direct stayed round topped boiler, whilst undoubtedly its first cost is greater. This view is supported by the experience of American and Continental engineers, where the use of the direct stayed round topped boiler is most generally adopted for all new engines.

Another feature worthy of note in modern engines is the tendency towards greater accessibility of working parts. Outside cylinders and particularly outside Walschaert valve gear, offer great advantages. It is possible to secure better cross bracing of the frames, to say nothing of easier oiling, inspection and maintenance of the motion. With such an engine it is not necessary to put it over a pit before leaving the shed and the essential parts can be better examined in a good light, a very important consideration. You cannot see well underreath an engine in a shed, and light is a great advantage.

The use of mechanical lubricators for axleboxes has also tended to simplify the work of the enginemen, the oiling of all the boxes being controlled by one lubricator. There has been a marked decrease in the number of hot boxes and an economy in the consumption of oil due to the fact that when an engine is standing no oil is being used. It is an important point that the mechanical lubricator should be connected to a point in the motion which has a constant travel and not to the valve spindle, of which the travel is reduced as the engine is notched up.

Now I am going to touch upon dangerous ground. As to the future, the subject that is claiming the attention of locomotive engineers to-day is the suggested standardisation of locomotives in England. 
his James Forrest lecture before the Institution of Civil Engineers twelve months ago. I believe I was the only locomotive engineer of any of the principal English railways present on that occasion, and have a lively recollection of the caustic remarks made to me subsequently by some of my friends who were there.

Sir John was in the same happy position as I am to-day, in that he was delivering an address and not reading a paper; therefore his remarks were not subject to subseque:it discussion.

He stated that the locomotive engineers were responsible for this absence of standardisation, and attributed the lamentable fact to these causes--that every British Company kept to its own type and acted on the supposition that eaci railway must have engines suitable to its own local conditions, but he confidently submitted that there was nothing to support such a contention. In India a broader view was taken. The movement has been a great success, and has saved India a very large sum of money, and it was very much to be wished and hoped for that, if a more centralised control of British railways became a fact the locomotives in this country would be dealt with as they had been in our great Dependency.

Now let me say at once that I am a strong advocate of standardisation in principle, but not necessarily of standardised locomotives, but the present is, in my opinion, the most inopportune moment for the introduction of the standard engine. After three and a half years of the greatest war the world has ever known, we are hard put to it to carry on the railway transportation of the country. The continued and increasing restrictions in the railway service are sufficient evidence of the difficulties with which we have to contend. To add to these by the introduction of several new types of standard engines, having new standards for such parts as brake blocks, firebars, valves, piston rings, and a hundred others, which constantly require renewal, and of which stocks have to be kept in the various depots all over the country, would be the height of folly and could only result in disaster.

Supposing for the sake of argument that the type of one Railway Company were adopted without modification. That Company would be no better off from a maintenance standpoint than they are to-day; possibly they might get their new engines a bit cheaper; but every other railway which purchased or built any new standard engines would 
have to provide in its works new patterns, templates, flanging blocks, etc., and in all its running sheds would have to keep complete stocks of the spare parts, which are required to effect the ordinary running shed repairs. You have only got to think of it. It could not be a more inopportune time to start.

It cannot be really seriously suggested that the interests of the country can be served by the immediate adoption of a standard engine, and I do not for one moment believe the late Sir John Wolfe Barry ever intended that his suggestions should be acted upon until after the war.

As to the general question of standardisation after the war, I suggest that this should be the subject for one of our papers during the coming session. It is a subject which can be ventilated and discussed with advantage by this Institution.

A few months ago $I$ was reading a very interesting address, given to one of the American Societies, in which the writer said, with regard to locomotives, it has been comparatively easy to make them bigger and heavier, but a greater and far more difficult problem faces us to-day, viz., that of making every pound of weight justify itself in terms of power.

Undoubtedly engines are approaching their maximum weights and sizes in this country, but are a long way from attaining their maximum power. IVe can, and shall have to, get more power per unit of weight.

The most efficient boiler is the one which absorbs the maximum amount of heat from the coal burnt per unit of weight; to produce more power without increasing the weight is one of the problems to be faced. How is this to be done? One obvious way is to pre-heat the feed water; very little has been done so far in the matter of really satisfactory feed water heating. Many arrangements have been applied, but none have yielded such striking results as to justify their general adoption. In most cases, owing to the heaters getting blocked up, their efficiency is so much reduced that there is no return for the extra cost of fitting and maintenance.

But the possibilities are far greater than is generally recognised. It is calculated, and I have no reason to doubt the accuracy of the figure, that roughly three-quarters of the heat which is generated in the firebox of a locomotive is wasted up the chimney. This does not mean that a locomo- 
tive boiler has an efficiency of 25 per cent. only-the efficiency is somewhere nearer 70 per cent., because of the heat wasted up the chimney, more than two-thirds is in the exhaust steam and the rest in the fiue gases.

The economy to be obtained by the introduction of a really satisfactory feed water heater is second only to the economy which has resulted from superheating.

The advantages of feeding a boiler with hot water are obvious, but to secure the ideal result the temperature of the feed water must be pre-heated to that of water already in the boiler; troubles such as leaking tubes and broken stays would then practically disappear, and the amount of water evaporated per pound of coal would increase to a surprising extent.

To raise one pound of water from 60 degrees $F$. to the temperature of a boiler with $200-1 b s$. pressure absorbs about $330 \mathrm{BTU}$; to evaporate that water absorbs a further 840 BTU; to superheat the steam produced by a further 200 degrees $F$. requires I IO BTU, making a total of say $I, 300$ BTU to raise the temperature of one pound of water from 60 degrees to 600 degrees F. Now if 200 or 300 of these units can be saved out of 1,300 by pre-heating the feed water, it gives you an idea of the possibilities to be obtained from the use of feed water heating and the enormous annual saving which would be effected.

The locomotive boiler should not be required, as it is to-day, to heat up its feed water, and should only be called upon for evaporation and superheating; but the problem is by no means easy. The smoke box gases and the exhaust steam are the two sources from which heat, which would otherwise be wasted, can be obtained. The former offers the best promise at first sight because the temperature of the smoke box gases is so much higher than that of exhaust steam; but owing to the rate of heat transference from hot gas to water being much less than that from exhaust steam to water, a much larger type of heater must be used in this case than if the feed water heater were arranged for exhaust steam. The weight factor therefore comes against us and is almost prohibitive.

Exhaust steam heaters, owing to the lower temperature of the steam, can only pre-heat water to about 200 degrees F., which is not sufficient.

Assuming that owing to weight the waste gas heater is ruled out, then we must turn to a live steam heater to 
complete the raising of the temperature to that of the water in the boiler.

Live steam heaters have proved in marine work to be economical because to feed a boiler with practically boiling water increases the boiler efficiency. Although there is extracted from the live steam as much heat as is absorbed in the feed water, on the other hand the amount of heat transferred from the furnace to the water is increased. Heat transference through a furnace plate or tube is much more rapid with hot water than with cold, hence the economy of live steam feed heaters.

Top feeds are a form of live steam feed water heating, and the good results obtained in continuous service are due to the fact that the feed water is in direct contact with the steam; therefore the formation of scale does not interfere with its action.

Exhaust heaters made on the lines of surface condensers fall off very rapidly in efficiency owing to scale formation. You want some arrangement by which the steam comes into direct contact with the water to be heated.

The designs of grates have shown no marked improvement for many years. This is a very important point in locomotive design to which no special attention has been paid, yet in giving the leading dimensions of an engine the grate area has always been one of the cardinal points. Grates cannot be made much larger, but they can be made more efficient. American engineers have been devoting considerable attention to this subject. Conditions requiring the maximum power demand that the air spaces between the bars shall be as large as the character of the coal burnt will permit without actual waste of unburnt coal through the spaces between the bars. I know lately some considerable progress has been made in the design of grates and also ashpans. In the arrangement of the ashpan itself, unless properly designed, the advantage which might be expected from an improved grate may be nullified.

Considerations of ease of maintenance have largly influenced firebox design. If more units of work have to be obtained per unit of weight out of locomotive boilers, the fireboxes will have to be designed to give more complete combustion and possibly with the provision of combustion chambers and auxiliary air supplies.

This leads to another consideration-the burning of pulverised fuel, by which an intense heat can be generated and almost perfect combustion obtained. The fire can be 
regulated with the greatest ease by varying the supply of powdered fuel. When an engine is standing very little coal is burnt, but in a few moments an intense fire can be obtained when the engine is required to start. Of course that may set up other troubles, such as leaky tubes, due to excessive local heating. But there is no doubt about this, that with pulverised fuel an intensity of heat can be obtained far greater than that from coal burnt in the ordinary way, and in consequence the capacity of a boiler for generating steam can be increased.

I have confined my remarks so far to locomotives, but it must not be taken to imply that there is not the same scope for development in the carriage and wagon department.

Had it not been for the war the construction of steel carriages would have been developed to a surprising degree in this country, and after the war is over, the shortage of timber, or rather the shortage of shipping for the importation of foreign timber, will afford a further inducement for effecting this radical change.

I believe that there is a future in the use of multiple bogie coaches. A few coaches roo-ft. long, carried on three bogies, are now running on the Great Northern. The use of this system effects a reduction of about 10 per cent. in the weight of the train, and the smooth running of coaches made on this system is admittedly superior to that of coaches carried on two bogies.

With regard to wagons. the first thing that is required in this country is a standardised wagon. Wagons are now ubiquitous owing to the common user arrangement, and it is difficult to imagine that the old wasteful practice by which wagons were returned empty to the owning Company's system can ever be reverted to.

The lack of standardisation, however, has been a difficulty, and it is very necessary that no time should be lost in producing a design of open and covered wagon which shall be standard for all the British railways.

Of course it is all very well talking about the future, making plans and considering ideals, but the energies of everybody here must be concentrated on the work of the moment-the winning of the war.

When this has been accomplished, be it this year, next year, or even longer, though it is hard to believe that the Germans can carry on very much longer, when this has been 
accomplished, I say, then it will be the time for the locomotive engineers to bring their broadened experiences to bear on the great problem of transportation, and apply to the railways at home and in our Colonies the engineering knowledge, experience, and, most important of all, the engineering adaptability which this, the greatest of all wars, has taught us.

Colonel Kitson Clark: Gentlemen, I have been selected, and $I$ am very willing to accept, the office of proposing a vote of thanks to our Chairman for his excellent address. With such a large meeting it would be wrong for me to take up much time in a talk, or to give voice to the criticisms of the address which I should like to develop. This I leave to the members of the Institution, but I feel quite certain there is one matter about which there will be no discussion. It is that we are all delighted that Mr. Gresley has taken the position, and our pleasure is increased after hearing the way in which he has handled his subject this afternoon. He impressed upon us a very important fact. You may make a very fine machine, but if you do not feed it you cannot get very much work out of it. We all understand what rationing means, and we know the limit of our capacity is in that portion of the anatomy which is our boiler and our firegrate. We at least discover for ourselves that we can do no more than our boilers will allow us to do.

My memory goes back longer than Mr. Gresley's. It was mor than 30 years ago when I began to understand about engines, and if it is not too much of a confession I would like to tell you I had devoted my education to classics rather than engineering, and happily so, for when I came to look round the works the first time, I asked my friend-" I would like you to tell me the difference between a cylinder and a boiler." He was able to tell me, and that was about as much as he knew. It was not very long before I came to the conclusion that the boiler was the thing, and $I$ have always been of the opinion that boilers are too small. $\mathrm{Mr}$. Brocklebank, who has designed great quantities of engines with very great success, has always coupled this great problem of economy with that of power, very wisely, and out of that arises a question which I should like to ask Mr. Gresley. We all agree you want your boiler to be capable of the best work. We all agree you must have a standard engine, and I do not agree that it is to be put off to the end of the war, but claim that we must begin thinking about it now. We have now got to make up our minds as to what waste we are going to incur when we put our standard 
engines to work on sections where the boiler capacity is not required to fill the cylinders. The question will be quite clear to you. There will be certain types which will exact every pound of steam which can be got out of the boiler, and the boiler must be made equal to it. Are there any statistics made, or calculations possible, which will give us an idea of the waste entailed in using a boiler which is too large for its work? Grate area and design of the damping, accuracy in designing the openings of the ashpan, and designing of smoke boxes are all matters by which the consumption of fuel may be curtailed when the boiler is too large for its work. This I submit is a very big question. Mr. Gresley will not answer it now, because he delivered an address, and not a paper, though I am convinced that he knows the answer. I submit that question is the one fundamental thing which decides the introduction of the standard engine.

But I should like to ask another question of Mr. Gresley. Can you tell us the exact difference in the power of turning water into steam when we have a locomotive boiler standing still, and when you have it running at ten miles an hour, and forty, and sixty miles an hour, on a good line like the Midland or the Great Northern? What is the actual difference caused by the plunging about of boilers when on the move?

I once made an invention, but, like many other patents, it was no good. Like many another inventor dealing with his own child, I thought it was good, but my friends differed from me. My invention had something to do with the transference of boiling water from the hotter portions of the boiler to the coider portions, in other words, circulation. It came to nothing, but I still believe in the poor thing, and hope someone else will solve the problem in a better way some day.

I wish to thank Mr. Gresley in your name and say I thoroughly enjoyed his inaugural address, and suggest that he gives another. You will thank him with me, I know, and I propose a vote of thanks to Mr. Gresley. (Applause).

Mr. A. C. Stamer (N.E.R., Darlington): I have had the horiour to be asked to second the vote of thanks to $\mathrm{Mr}$. Gresley for his interesting paper. He has touched upon a large number of subjects which would lend themselves to papers instead of an address. We are not allowed to discuss the address, but the various matters touched upon would form the subject of interesting papers. In the first 
instance he said very little upon the Great Northern Railway and the performance of its locomotives.

I should like to say that we are partners in the East Coast, and we are perhaps a mutual admiration society, any way as regards locomotive work.

As an instance take the 5.30 p.m. train out of King's Cross Station. It is a heavy train-500 tons-with a gradient at the start all against the engine. It is a rising gradient of $I$ in 70 , and the work of the Great Northern locomotives on that gradient has always filled me with admiration.

The engines, I believe, were not built by Mr. Gresley, but by his predecessors, whose records are the best in the locomotive world; such names as Mr. Patrick Stirling and Mr. Ivatt will live in locomotive history, and we all hope that Mr. Gresley's will rise still higher in the near future.

It is quite refreshing to get a bit of good locomotive talk and to get away from the atmosphere of war bonuses, and any mention of $12 \frac{1}{2}$ per cent., of which one's life seems at present to be made up. To be present at a meeting like this is really very refreshing.

Mr. Gresley succeeded in bringing before the meeting a lot of subjects. He has obviously in view their embodiment in papers to be read before the members of the Centre in the coming session. One feels it impossible to even mention the majority of them without inviting a wide field for instructive discussion. The wide firebox is mentioned. It appears that it has been a success, but I notice he has not produced it on any of his own engines. That is a point on which I should like to know the reason. With regard to Walschaert valve gear, it does not appear to me to show superiority over the old-fashioned Stephenson link motion

The question of standardisation is one which Colonel Kitson Clark touched upon. I am not going to talk about it because $I$ think it is a question we shall have to discuss in the near future. With regard to standardisation between Railway Companies for locomotives, there does not appear to me to be much reason for it. But every railway company ought to standardise amongst its own engines. Standardisation opens a very wide field for discussion.

Mr. Gresley did not touch upon the influence of electrification in the future. I still think that the good old steam locomotive will hold the field for some time. 
With regard to electrification, we have experimented with electric locomotives, as you know, on the North Eastern. We have a small portion of our line electrified. That is the line from Shildon to Newport, near Middlesbrough. It is a mineral line entirely, operating the gathering ground of the coalfield for the coal supply to the Middlesbrough district, and about $18 \frac{1}{2}$ miles have been electrified for $2 \frac{1}{2}$ years. The experiment has certainly been justified, and we are well pleased. I think the whole question depends entirely upon the supply of current and its cheapness, and the iength of transmission. We find as far as our electric locomotives are concerned that the loads they haul are as good as, and more than, in some cases what are hauled by heavy steam locomotives. The chicf advantage is the quick acceleration, and we have been able to shorten the time taken in covering the distances.

But I think it will be a long time before main lines are electrified and the steam locomotive goes into the museum or into its grave, and for that reason there is still scope for its improvement and development.

The question of the large boiler, which Mr. Gresley mentioned, is the heart and soul of the engine. I agree with every word he said with regard to the size and capacity of the boiler.

Gentlemen, I only got up to second a vote of thanks to Mr. Gresley, and I trust that this local Centre at Leeds will have a very flourishing career. We have made a good start, and hope to have many visits to works during the summer, and meetings during the winter months.

I have much pleasure in seconding a vote of thanks to Mr. Gresley for his most interesting address.

Colonel Kitson Clark: I put it to you, gentlemen-the motion. Those in favour $I$ ask to hold up their hands. If there is anyborly who has got a message that he can deliver in five or ten minutes, I am in charge of the house, and I think Mr. Gresley would allow it. The only motion there is going to be put to-day is a hearty vote of thanks to the Chairman. Has anybody got anything to say? Shall this motion be carried?

The motion was carried unanimously.

The Chairman : Colonel Kitson Clark, Mr. Stamer, and Gentlemen, I thank you very much for the way in which you have received my address. Several points were raised in proposing the resolution, but, of course, the Chairman has 
214 JOURYAL OF THE INST. OF LOCO. ENGINEERS.

the power of exercising his right of directing the proceedings of the meeting, and I am not going to be drawn into a discussion.

There is just one point. It is in reference to an observation of my friend on the left. He asks, "Why not a wide firebox?" The answer is that we have not had an engine to build which was big enough. If, and when, it is necessary to build an engine of that type it will certainly be: considered. I thank you very much for your attention. 